\title{
Characterization and Singlet Oxygen Quenching Capacity of Spray-Dried Microcapsules of Edible Biopolymers Containing Antioxidant Molecules
}

\author{
Adelia F. Faria, ${ }^{\dagger}$ Ricardo A. Mignone, ${ }^{*}$ Mariana A. Montenegro, ${ }^{\S}$ \\ Adriana Z. Mercadante, ${ }^{\dagger}$ and Claudio D. Borsarelli* $*$ \\ ${ }^{\dagger}$ Department of Food Science, Faculty of Food Engineering, University of Campinas (UNICAMP),

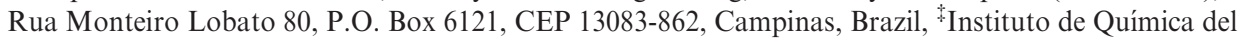 \\ Noroeste Argentino (INQUINOA-CONICET), Facultad de Agronomía y Agroindustrias, Universidad \\ Nacional de Santiago del Estero (UNSE), Av. Belgrano (S) 1912, G4200ABT, Santiago del Estero, \\ Argentina, and ${ }^{\S}$ Departamento de Química, Facultad Regional Villa María, Universidad Tecnológica \\ Nacional (UTN-VM), Av. Universidad 459, 5900, Villa María, Argentina
}

\begin{abstract}
Microcapsules of gum arabic or maltodextrin 20DE containing antioxidant molecules (AOx), for example, carotenoids and tocopherol derivatives, were prepared by the spray-drying technique. The properties of these microcapsules were evaluated by several techniques, such as dynamic light scattering, scanning electronic microscopy, and steady-state and time-resolved fluorescence spectroscopy of microencapsulated pyrene. The quenching of photochemically generated singlet molecular oxygen $\left({ }^{1} \mathrm{O}_{2}\right)$ by the $\mathrm{AOx}$ in homogeneous solvents as well as in microcapsule solutions was evaluated using time-resolved phosphorescence detection of ${ }^{1} \mathrm{O}_{2}$. The quenching rate constant of the process, ${k_{\mathrm{Q}}}^{\mathrm{AOx}}$, was strongly dependent on the type of the AOx. These results are explained by compartmentalization effects of the $\mathrm{AOx}$ in the core of the microcapsules and the accessibility of ${ }^{1} \mathrm{O}_{2}$. The contribution of the biopolymer as quencher of ${ }^{1} \mathrm{O}_{2}$ was also investigated. The present results can be applied to the design of edible antioxidant microcapsules within the food and cosmetic industries.
\end{abstract}

KEYWORDS: Microencapsulation; carotenoids; tocopherols; singlet oxygen; antioxidant activity; spray drying; pyrene fluorescence

\section{INTRODUCTION}

Singlet molecular oxygen $\left({ }^{1} \mathrm{O}_{2}\right)$ is the lowest excited state of the ground triplet state of molecular oxygen $\left({ }^{3} \mathrm{O}_{2}\right)$, with $94 \mathrm{~kJ} / \mathrm{mol}$ of excitation energy and a lifetime of several microseconds $(1,2)$. Because of these properties and its ubiquity in chemical and biological media, this nonradical species reacts efficiently with most electron-rich ground state singlet state molecules to form primary oxidation products, for example, hydroperoxides, dioxetanes, epoxides, endoperoxides, etc. (3). The reactivity of ${ }^{1} \mathrm{O}_{2}$ in food induces the formation of off-flavors and loss of nutritional value; hence, the development of new technologies that prevent these undesired effects is a relevant issue for the food industry (4).

The generation of ${ }^{1} \mathrm{O}_{2}$ in solution can be achieved in several ways, for example, chemically, enzymatically, and photochemically $(1-4)$. In the last case, many compounds found naturally in foods act as sensitizers (S), absorbing UVA and/or visible light to form singlet and/or triplet excited states $\left(\mathrm{S}^{*}\right)$, which via energy transfer to ${ }^{3} \mathrm{O}_{2}$ with a quenching rate constant $k_{\text {et }}$ generate the ground state of the sensitizer and

*To whom correspondence should be addressed. Tel/Fax: +54-3854509528. E-mail: cborsarelli@yahoo.com.ar or cborsar@gwdg.de.
${ }^{1} \mathrm{O}_{2}$ (eqs 1 and 2, respectively):

$$
\begin{gathered}
\mathrm{S} \stackrel{h v}{\rightarrow} \mathrm{S}^{*} \\
\mathrm{~S}^{*}+{ }^{3} \mathrm{O}_{2} \stackrel{k_{\text {et }}}{\rightarrow} \mathrm{S}+{ }^{1} \mathrm{O}_{2}
\end{gathered}
$$

In this type of mechanism, the harmful activity of ${ }^{1} \mathrm{O}_{2}$ can be prevented by blocking of the excitation light $(h v)$, with either internal or external filters, and/or by efficient deactivation of $\mathrm{S}^{*}$ and/or ${ }^{1} \mathrm{O}_{2}$ by quencher molecules (Q) through chemical and/or physical quenching processes (eq 3).

$$
\mathrm{S}^{*} /{ }^{1} \mathrm{O}_{2}+\mathrm{Q} \stackrel{k_{\mathrm{Q}}}{\rightarrow} \mathrm{S} /{ }^{3} \mathrm{O}_{2}+\mathrm{Q} \text { and/or products }
$$

In this process, $k_{\mathrm{Q}}$ is the bimolecular rate constant for the total quenching, which in turn is the sum of the rate constants of chemical and physical quenching, that is, $k_{\mathrm{c}}$ and $k_{\mathrm{p}}$, respectively. The chemical quenching leads to the consumption of the excited state and the quencher with the formation of oxidation products. In contrast, the physical quenching of the excited states by the quencher occurs by a variety of dissipative mechanisms that regenerate the reaction partners in their electronic ground state. Typically, in air-saturated solutions, 
the molecular oxygen concentration is high enough for an almost complete quenching of the excited triplet state of the sensitizer to produce ${ }^{1} \mathrm{O}_{2}$ (eq 2) (5). Therefore, the efficient deactivation of ${ }^{1} \mathrm{O}_{2}$ by quencher molecules prior to its reaction with functional molecules (e.g., proteins, lipids, DNA, etc.) is crucial to prevent the oxidative damage (antioxidant action) (6). Along with other antioxidant molecules (AOx), the carotenoids and tocopherols also act as efficient quenchers of ${ }^{1} \mathrm{O}_{2}(7-11)$. In the case of foods, this antioxidant action contributes to a superior product stability and, therefore, to an increased consumer acceptance (12). However, most of these antioxidant molecules are poorly soluble in aqueous media, and as is the case of carotenoids, they are also quite susceptible to degradation under high temperature, low $\mathrm{pH}$, and the presence of light and oxygen, among other factors commonly found during food processing $(13,14)$.

To overcome these issues, spray-drying microencapsulation was developed as a practical and economically suitable methodology for preserving and carrying labile food ingredients, such as flavors, lipids, and carotenoids (15). During this process, a liquid solution of a biopolymer and the molecule of interest are atomized for few seconds in a hot gas flow to instantaneously obtain a powder. This material consists of tiny core particles or droplets of the active material surrounded by a coating matrix composed of the biopolymer (15).

Among the diversity of biopolymers used in spray-drying processes, gum arabic (GA) and maltodextrins (MDs) are extensively utilized for microencapsulation of labile or valuable food ingredients, improving their stability and controlled delivery $(16,17)$. However, to the best of our knowledge, few studies have been done to properly characterize the antioxidant properties of these materials (4). In a previous work, we demonstrated that the protective effect of vitamins $\mathrm{A}, \mathrm{D}_{3}$, and riboflavin in irradiated skimmed milk containing lycopene-GA microcapsules was mainly due to the efficient quenching of the excited triplet state of riboflavin by GA itself, demonstrating the additional functionality of this glycoprotein to prevent photo-oxidation processes (4).

Considering the intrinsic ability of carotenoids and tocopherols to quench ${ }^{1} \mathrm{O}_{2}$ in lipophilic media $(7-11)$, in the present study, we explored the ${ }^{1} \mathrm{O}_{2}$ quenching capacity of microcapsules of $\mathrm{GA}$ or MD containing the carotenoid or tocopherol derivatives shown in Figure 1. Furthermore, we determined some of the structural and morphological properties of the microcapsules. The present results can be applied to the design of edible microcapsules with antioxidant functionality.

\section{MATERIALS AND METHODS}

Materials. $\alpha$-Tocopherol, 6-hydroxy-2,5,7,8-tetramethylcroman-2carboxylic acid (trolox), $\beta$-carotene, rose bengal, and pyrene (Py) were obtained from Sigma-Aldrich (MO). Apo-8'-carotenal and apo-12'-carotenal were kindly donated by DSM Nutritional Products (Basel, Switzerland). These compounds were used as received, with the exception of $\beta$-carotene, which was recrystallized up to $98 \%$ purity, as monitored by highperformance liquid chromatography (HPLC). Powdered GA (MW = $3.5 \times 10^{5} \mathrm{~g} / \mathrm{mol}$ ) was supplied by Colloids Naturels Brasil (São Paulo, Brazil), and maltodextrin 20DE (MD, MW $=1000 \mathrm{~g} / \mathrm{mol}$ ) was supplied by Corn Products Brasil (Mogi Guaçu, Brazil). Organic solvents, analytical grade, were obtained from Sintorgan (Buenos Aires, Argentina), and deuterium oxide (99.9\% purity) was from Sigma-Aldrich. Aqueous solutions were prepared with Milli-Q quality water.

Preparation of Microcapsules. The microcapsules were prepared using a laboratory-scale spray-drier system Lab Plant SD-04 (Huddersfield, United Kingdom), under the following working conditions: aspersion nozzle diameter of $0.7 \mathrm{~mm}$, air pressure of $5 \mathrm{kgf} / \mathrm{cm}^{2}$, air flow rate of $30 \mathrm{~mL} / \mathrm{min}$, and entrance and exit air temperatures of 170 and $110^{\circ} \mathrm{C}$, respectively. Solutions<smiles>CC1=C(/C=C/C(C)=C/C=C/C(C)=C/C=C/C=C(C)/C=C/C=C(C)/C=C/C2=C(C)CCCC2(C)C)C(C)(C)CCC1</smiles><smiles>CC1=C(/C=C/C(C)=C/C=C/C(C)=C/C=C/C=C(C)/C=C/C=C(\C)C=O)C(C)(C)CCC1</smiles><smiles>CC1=C(/C=C/C(C)=C/C=C/C(C)=C/C=C/C=C(\C)C=O)C(C)(C)CCC1</smiles>

Apo-12'-carotenal<smiles>Cc1c(C)c2c(c(C)c1O)CCC(C)(CCCC(C)CCCC(C)CCCC(C)C)O2</smiles><smiles>Cc1c(C)c2c(c(C)c1O)CCC(C)(C(=O)O)O2</smiles>

Trolox

Figure 1. Structures of carotenoid and tocopherol derivatives.

of each biopolymer [ $200 \mathrm{~mL}$ of solution at $30 \%(\mathrm{w} / \mathrm{v})$ of soluble solid] were prepared in water at $45^{\circ} \mathrm{C}$ to obtain a complete dissolution of the biopolymer and were kept under continuous stirring until the temperature reached $30^{\circ} \mathrm{C}$. Each AOx (15-63 mg) was dissolved in a suitable solvent (dichloromethane for carotenoids and ethanol for tocopherol derivatives) and added to the polysaccharide solution. The mixture was homogenized at $7000 \mathrm{rpm}$ for $30 \mathrm{~min}$, and afterward, the emulsion was diluted with water to obtain a $20 \%$ $(\mathrm{w} / \mathrm{v})$ biopolymer solution. The emulsion was placed in the spray-drier chamber, maintaining slow agitation during the spray-drying process. The microcapsules obtained were immediately stored in a glass bottle under $\mathrm{N}_{2}$ atmosphere at $-36{ }^{\circ} \mathrm{C}$ to avoid $\mathrm{AOx}$ degradation.

To characterize the microcapsule microenvironment, we prepared microcapsules containing different amounts of Py. The same procedure for microencapsulation of carotenoids was utilized. The total Py concentration within the microcapsules was estimated by measuring the absorbance band of Py at $336 \mathrm{~nm}$ using $\varepsilon=5.6 \times 10^{4} / \mathrm{M} \mathrm{cm}$ (18), after exhaustive extraction with dichloromethane and an ethanol 1:1 mixture. The final molar concentrations of Py per gram of dry biopolymer for the both microcapsule series were $0.26,1.74$, and $4.13 \mu \mathrm{mol} / \mathrm{g}$ for GA and 0.02 , 0.05 , and $0.06 \mu \mathrm{mol} / \mathrm{g}$ for MD.

Microencapsulation Efficiency (ME). This parameter was determined according to Nunes and Mercadante (19), and it is defined as the percentage of antioxidant molecules in the core of the microcapsule in relation to its total (core + surface) concentration. Briefly, the total carotenoids were extracted exhaustively with dichloromethane from MD or GA microcapsule solutions in water or water:methanol (2:3), respectively. The carotenoids located on the surface of microcapsules were directly extracted with dichloromethane from powdered microcapsules. In both analyses, the organic phases were recovered in a separation funnel and dried with anhydrous $\mathrm{Na}_{2} \mathrm{SO}_{4}$. Afterward, the organic solvent was removed under vacuum in a rotary evaporator $\left(T<35^{\circ} \mathrm{C}\right)$, and the carotenoids were redissolved in petroleum ether for quantification by UV/vis absorption spectroscopy, using an Agilent 8453 diode array 
spectrophotometer (Santa Clara, United States). Carotenoid concentrations were calculated according to their absorptivity values $\left(E_{1 \mathrm{~cm}}{ }^{1 \%}\right)$ at maximum wavelength, as reported by Davies (20).

For microcapsules containing tocopherol derivatives, the total AOx content was determined in aqueous solutions by measuring the tocopherol and trolox absorbances at $290 \mathrm{~nm}$ subtracting the background absorbance and/or scattering of the "empty" microcapsule solution at the same biopolymer concentration. The antioxidant content on the surface of the microcapsule was determined by extraction with ethanol, and the supernatant was separated by centrifugation (4000 rpm). The supernatant was dried with anhydrous $\mathrm{Na}_{2} \mathrm{SO}_{4}$ for 30 min and filtered; the solvent was then removed under vacuum at $35{ }^{\circ} \mathrm{C}$. The extracted tocopherols were redissolved in a small volume of ethanol and quantified spectrophotometrically at $290 \mathrm{~nm}$, using calibration curves of standard AOx in ethanol solution with concentrations between 60 and $300 \mu \mathrm{M}$.

Microcapsule Properties. The particle size diameter and distribution of the microcapsules were obtained by dynamic light scattering (DLS) measurements using the Malvern-Mastersizer S-MAM-5005 equipment (Worcestershire, United Kingdom). The microcapsules $(5 \mathrm{mg} / \mathrm{mL})$ were suspended in isopropyl alcohol, a solvent in which the microcapsules are slightly soluble. The data were collected as a series of five measurements of duplicate microcapsule suspensions.

The morphology of the microcapsules was evaluated by scanning electronic microscopy (SEM) with a JEOL JSM 5800 LV apparatus (Tokyo, Japan), using an acceleration voltage of $10 \mathrm{kV}$. The microcapsules were fixed in stubs containing a double-faced adhesive metallic tape and coated with gold in a Balzers evaporator SCD 050 (Vienna, Austria) during $75 \mathrm{~s}$ with a $40 \mathrm{~mA}$ current.

The microenvironmental properties of the microcapsules were analyzed by the fluorescence of microencapsulated Py using a Hitachi F-2500 spectrofluorometer (Kyoto, Japan). In all cases, the concentration of the biopolymer was $5 \mathrm{mg} / \mathrm{mL}$. Excitation and emission spectra were registered with bandwidth slits of $2.5 \mathrm{~nm}$. The fluorescence intensity ratios between the first $(371 \mathrm{~nm})$ and the third $(382 \mathrm{~nm})$ vibronic bands, $I_{1} / I_{3}$, and between the excimer $(460 \mathrm{~nm})$ and the monomer $(371 \mathrm{~nm})$ of Py molecules, $I_{\mathrm{E}} / I_{\mathrm{M}}$, were monitored by excitation at $326 \mathrm{~nm}$. Fluorescence lifetime measurements were performed with a Tempro-01 lifetime spectrofluorometer from Horiba-Jobin Yvon IBH (Glasgow, United Kingdom) using as the excitation source a high-speed LED at $340 \mathrm{~nm}$ and an emission bandwidth of $8 \mathrm{~nm}$. The fluorescence decays were analyzed with the DataStation v6.5 software using a multiexponential function (eq 4), with $\tau_{i}$ and $a_{i}$ as the lifetime and pre-exponential factor of the $i$-th decay component, respectively.

$$
I(t)=\sum_{i} a_{i} \mathrm{e}^{-\left(t / \tau_{i}\right)}
$$

The solutions were previously purged with water-saturated argon during 15 min to minimize the quenching effect by molecular oxygen. In addition, the quenching of Py fluorescence by molecular oxygen was evaluated by bubbling $\mathrm{N}_{2} / \mathrm{O}_{2}$ mixtures of different compositions. The quenching rate constant of Py by $\mathrm{O}_{2}$, that is, $k_{\mathrm{Q}}{ }^{\mathrm{O}_{2}}$, was calculated with the classical Stern-Volmer (SV) eq 5, where $\tau$ and $\tau_{0}$ are the fluorescence lifetimes of Py in the presence and absence of molecular oxygen, respectively.

$$
\tau^{-1}=\tau_{0}{ }^{-1}+k_{\mathrm{Q}}{ }^{\mathrm{O}_{2}}\left[\mathrm{O}_{2}\right]
$$

Quenching of Singlet Molecular Oxygen. Photosensitized generation and transient phosphorescence detection of ${ }^{1} \mathrm{O}_{2}$ were performed as previously described (21). Briefly, $8 \mu \mathrm{M}$ rose bengal in air-saturated acetonitrile or $\mathrm{D}_{2} \mathrm{O}$ solutions was excited with laser pulses at $532 \mathrm{~nm}(10 \mathrm{~ns}$ fwhm, $3 \mathrm{~mJ} /$ pulse). The transient phosphorescence signal of ${ }^{1} \mathrm{O}_{2}$ was monitored at $1270 \mathrm{~nm}$ as a function of the quencher concentration with a Peltier-cooled Ge photodiode J16TE2-66G from Judson Technology (Montgomeryville, PA). The decay portion of the transient phosphorescence intensity $I_{(t)}$ was fitted as a first-order decay with eq 6 , with $I_{0}$ as the initial phosphorescence intensity and $\tau_{\Delta}$ as the observed decay time of ${ }^{1} \mathrm{O}_{2}$.

$$
I_{(t)}=I_{0} \times \exp \left(-t / \tau_{\Delta}\right)
$$

The decreases of $\tau_{\Delta}$ with the AOx (三 quencher) concentration allowed the calculation of the rate constant value for the total quenching of ${ }^{1} \mathrm{O}_{2}$
Table 1. Antioxidant Molecule Concentration, ME, and Average Diameter of the Spray-Dried Microcapsules Prepared with GA and MD

\begin{tabular}{clccc}
\hline biopolymer & AOx molecule & {$[\mathrm{AOx}]^{a}$} & $\mathrm{ME}(\%)^{b}$ & $\begin{array}{c}\text { average diameter } \\
\langle d\rangle(\mu \mathrm{m})\end{array}$ \\
\hline \multirow{6}{*}{$\mathrm{GA}$} & & & $9.6 \pm 0.2$ \\
& none & 2.60 & 80.7 & $9.0 \pm 0.2$ \\
& trolox & 1.55 & 80.0 & $10.3 \pm 0.4$ \\
& $\alpha$-tocopherol & 1.39 & 99.0 & $10.7 \pm 0.2$ \\
& $\beta$-carotene & 0.37 & 96.6 & $9.4 \pm 0.1$ \\
& apo-8'-carotenal & & \\
& apo-12'-carotenal & 0.53 & 94.9 & $8.9 \pm 0.1$ \\
& & & & \\
& none & & & $7.6 \pm 0.5$ \\
& trolox & 1.88 & 75.0 & $8.8 \pm 0.1$ \\
MD & $\alpha$-tocopherol & 2.13 & 73.0 & $7.7 \pm 0.1$ \\
& $\beta$-carotene & 1.04 & 63.9 & $7.1 \pm 0.1$ \\
& apo-8'-carotenal & 0.35 & 75.7 & $6.4 \pm 0.1$ \\
& apo-12'-carotenal & 0.55 & 92.8 & $7.4 \pm 0.2$ \\
\hline
\end{tabular}

${ }^{a} \mu \mathrm{mol}$ AOx molecule/g biopolymer $( \pm 5 \%) .{ }^{b} \pm 10 \% .{ }^{c}$ Determined by DLS and represents average particle diameter calculated as $\langle d\rangle=\left(f_{1} d_{1}+f_{2} d_{2}\right) / 100$, where $f_{1}$ and $f_{2}$ are the volume fractions of the smaller and larger particle populations with diameters $d_{1}$ and $d_{2}$, respectively.

(chemical + physical) by the $\mathrm{AOx}, k_{\mathrm{Q}}{ }^{\mathrm{AOx}}$ (eq 7), and $\tau_{\Delta, 0}$ represents the lifetime of ${ }^{1} \mathrm{O}_{2}$ in the neat solvent, which in the present study were $76 \pm 3 \mu \mathrm{s}$ in acetonitrile or $65 \pm 2 \mu \mathrm{s}$ in $\mathrm{D}_{2} \mathrm{O}$.

$$
1 / \tau_{\Delta}=1 / \tau_{\Delta, 0}+k_{\mathrm{Q}}{ }^{\mathrm{AOx}}[\mathrm{AOx}]
$$

All of the experiments were performed at $25 \pm 1{ }^{\circ} \mathrm{C}$ in duplicate, and the average $k_{\mathrm{Q}}{ }^{\mathrm{AOx}}$ value with its standard deviation was calculated.

\section{RESULTS AND DISCUSSION}

Microcapsule Properties. The concentration of the AOx incorporated into the microcapsules after spray drying ranged between 0.35 and $2.60 \mu \mathrm{mol} \mathrm{AOx/g} \mathrm{biopolymer,} \mathrm{and} \mathrm{it} \mathrm{was} \mathrm{almost}$ independent of the nature of the biopolymer for each type of $\mathrm{AOx}$ (Table 1). However, the ME value depended on the combination of AOx and biopolymer utilized. In particular, the carotenoids were almost fully incorporated into the core of the GA microcapsules $(\mathrm{ME}>95 \%$ ), but for the MD microcapsules, the ME value follows the trend apo- $12^{\prime}$-carotenal $(93 \%)>$ apo- $8^{\prime}$-carotenal $(76 \%)>\beta$-carotene $(64 \%)$, indicating a larger capacity of the MD to locate carotenoids with lower molecular weight into the core of the microcapsule. On the other hand, similar ME values were obtained for $\alpha$-tocopherol and trolox in both microcapsules. Thus, it can be assumed that only the chromanol ring of the tocopherol derivatives governs the interaction with the wall material of the microcapsules.

Figure 2A shows SEM micrographs of microcapsules of GA and MD containing apo-12'-carotenal. The surface morphology was independent of both the presence and the type of AOx molecules. In all cases, the microcapsules of GA showed more irregular surfaces than those prepared with MD. This effect is attributed to the different molecular composition of the biopolymers since the shrinkage of the particles during the drying process is influenced by the structure of the biopolymer used as wall material. A greater amount of low molecular weight residues on the surface of the biopolymer, which may act as a plasticizer preventing shrinkage of the surface during drying, produces a smoother surface (16). The biopolymers used in the present study corroborate these observations. GA is a complex and variable mixture of arabinogalactan oligosaccharides, polysaccharides, and glycoproteins, resulting in a high molecular weight biopolymer $(\mathrm{MW} \approx 350 \mathrm{kDa})(22)$. On the other hand, maltodextrin $(\mathrm{MW} \approx 1 \mathrm{kDa})$ is a mixture of short polymers of D-glucose (3-20 units), in which the $\alpha$-D-glucopyranosyl monomers are joined by $(1 \rightarrow 4)$ linkages to give linear chains with a certain 
degree of chain branching due to $(1 \rightarrow 6)$ bonding $(23)$. Therefore, MD produces microcapsules with a surface smoother than that formed by GA, as Figure 2A clearly shows. As depicted in Figure 2B, the plots of DLS for both types of microcapsules show similar size and particle distribution, with two main populations with volume
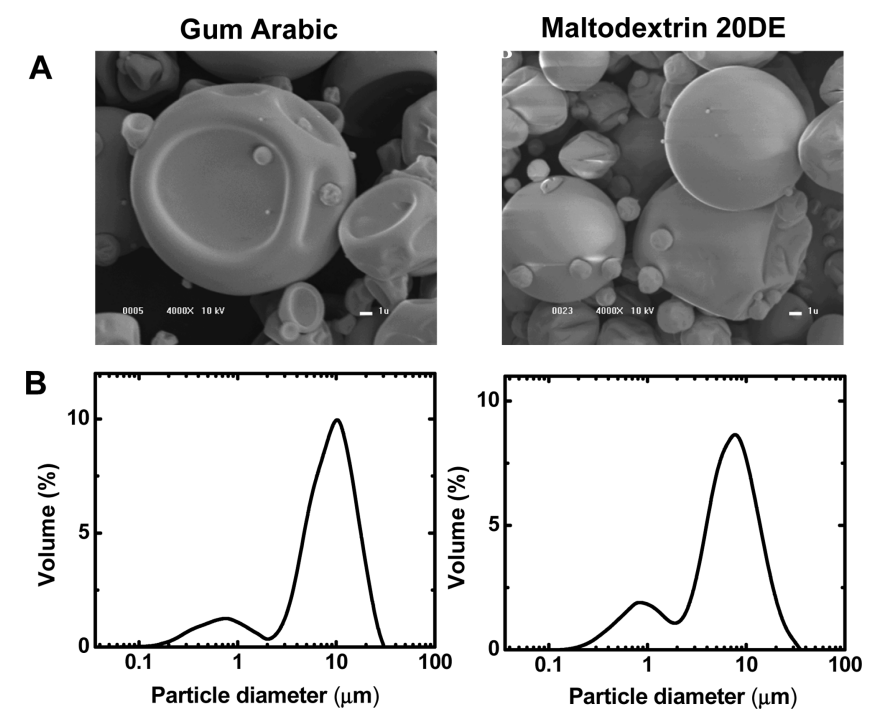

Figure 2. (A) SEM micrographs (magnified $4000 \times$; acceleration voltage of $10 \mathrm{kV}$ ) and (B) particle size distribution obtained by DLS measurements of $5 \mathrm{mg} / \mathrm{mL}$ microcapsules containing apo-12'-carotenal in GA and MD microcapsules. fraction $\left(f_{1}\right.$ and $\left.f_{2}\right)$ of 15 and $85 \%$ with diameter $\left(d_{1}\right.$ and $\left.d_{2}\right)$ of approximately of 0.9 and $10 \mu \mathrm{m}$, respectively. Both parameters for each type of microcapsule were also independent of the nature of the AOx (data not shown), confirming that the polydispersity degree in the size of the microcapsules is mainly governed by the setup conditions of the spray-drying procedure. Regardless, it is possible to calculate an average diameter $\langle d\rangle\left[=\left(f_{1} d_{1}+f_{2} d_{2}\right) / 100\right]$ of $9.7 \pm$ 0.7 and $7.5 \pm 0.8 \mu \mathrm{m}$ for GA and MD microcapsules, respectively.

On the other hand, it is well-known that the fluorescence of Py is very sensitive to microenvironmental solvent properties and self-concentration effects, and it is a useful tool for the characterization of both conformational and/or microenvironmental properties in supra- and macromolecular systems $(24,24)$. In MD microcapsules, only the typical monomeric excitation $\left(\lambda_{\mathrm{ex}}{ }^{\max }=\right.$ $335 \mathrm{~nm})$ and emission $\left(\lambda_{\mathrm{em}} \max =371 \mathrm{~nm}\right)$ spectra of Py were observed (data not shown). However, in GA microcapsules, the monomeric emission of Py was accompanied by the bluish emission of the excimer, that is, $(\mathrm{Py} \cdot \mathrm{Py})^{*}$ with $\lambda_{\mathrm{em}}^{\max }=460 \mathrm{~nm}$ (spectra 1-3 of Figure 3A). The emission band of the excimer was also observed with excitation at $355 \mathrm{~nm}$ (dashed line spectrum), where Py almost does not absorb. Moreover, the excitation spectrum monitored at $371 \mathrm{~nm}$ (spectrum 4) corresponded to that observed for a dilute solution of Py in organic solvents, whereas a much broader and structureless excitation spectrum was obtained by selecting the excimer emission at $460 \mathrm{~nm}$ (spectrum 5). The bluish emission cannot be associated to the background fluorescence contribution of the biopolymer, since the fluorescence of an "empty" GA microcapsule solution $(5 \mathrm{mg} / \mathrm{mL})$ was negligible as compared with that of Py.
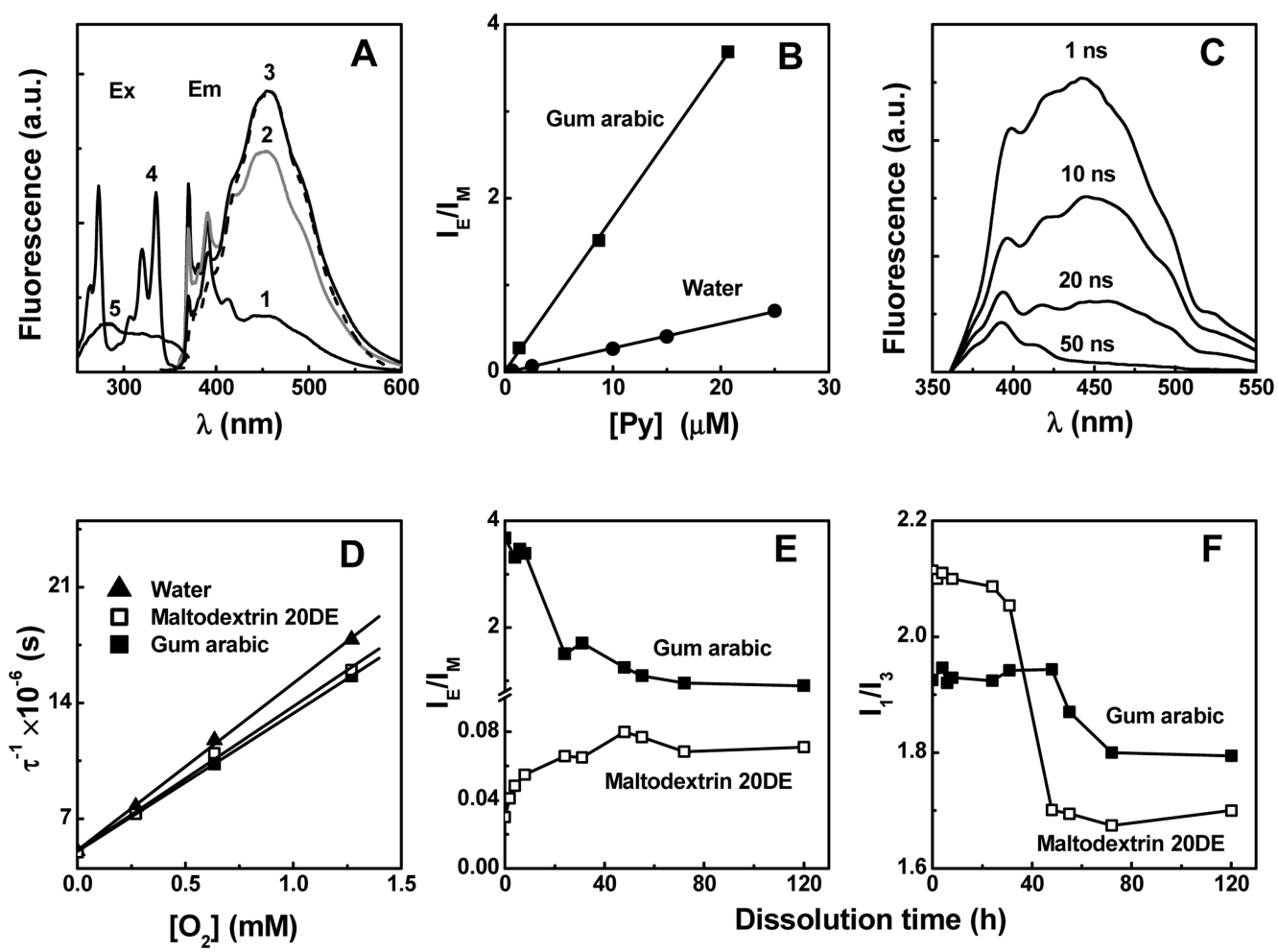

Figure 3. Fluorescence spectra and properties of $5 \mathrm{mg} / \mathrm{mL}$ microcapsule aqueous solution containing Py. (A) Emission spectra obtained with excitation at 326 $\mathrm{nm}$ of (1) 1.3, (2) 8.7, and (3) $20.7 \mu \mathrm{M}$ Py in GA microcapsules. Excitation spectra of $1.3 \mu \mathrm{M}$ Py monitored at emission wavelengths of (4) 371 and (5) $460 \mathrm{~nm}$. The dashed line represents the emission spectrum of $20.7 \mu \mathrm{M}$ Py obtained with an excitation at $355 \mathrm{~nm}$. (B) Dependence of the excimer-to-monomer ratio, $I_{E} / I_{M}$, in GA microcapsule and in aqueous solutions as a function of the Py concentration. (C) Time-resolved emission spectra (TRES) of $1.3 \mu \mathrm{M}$ Py in GA microcapsules with a data interval of $2 \mathrm{~nm}$ and different times after the excitation pulse at $340 \mathrm{~nm}$. (D) SV plots for the dynamic quenching of Py by dissolved molecular oxygen in water $([\mathrm{Py}]=0.7 \mu \mathrm{M})$ and in $5 \mathrm{mg} / \mathrm{mL}$ microcapsule solutions of $\mathrm{MD}([\mathrm{Py}]=0.3 \mu \mathrm{M})$ and $\mathrm{GA}([\mathrm{Py}]=1.3 \mu \mathrm{M})$. Dependence with the dissolution time in water of $(\mathbf{E})$ the $l_{\mathrm{E}} / l_{\mathrm{M}}$ ratio of 0.3 and $20.7 \mu \mathrm{M}$ Py in $5 \mathrm{mg} / \mathrm{mL} \mathrm{MD}$ and $\mathrm{GA}$ microcapsules, respectively, and (F) the vibronic band ratio $I_{1} / I_{3}$ ratio of 0.3 and $1.3 \mu \mathrm{M}$ Py in $5 \mathrm{mg} / \mathrm{mL} \mathrm{MD}$ and GA microcapsules, respectively. 
The same excimer emission was also observed in aqueous solution of $\mathrm{Py}$ in the concentration range of $2.5-25 \mu \mathrm{M}$. However, the excimer-to-monomer intensity ratio $I_{\mathrm{E}} / I_{\mathrm{M}}$ as a function of the Py concentration was almost six times larger in the GA microcapsule than in water solutions (Figure 3B), indicating that the local concentration of Py molecules is increased in this microcapsules. This effect can result from the more complex composition of GA and dented morphology of the GA microcapsules contributing to the increases of the effective surface and the amount of hydrophobic sites, favoring the excimer formation.

The formation of an excimer requires the pairing of two Py molecules in a sandwich configuration, where the excitation energy is delocalized by resonance between both molecules. Two mechanisms of excimer formation are normally operating, that is, in the "dynamic excimer", a ground state molecule interacts with an electronically excited state during its lifetime (25). In this case, the maximum of the excimer emission is around $480 \mathrm{~nm}$, independently of the solvent polarity, and the same monomer excitation spectrum is obtained by selecting either the emission maximum of the monomer or the excimer. However, under nondiffusion controlled conditions, such as in rigid covalently bonded dimers or in microheterogeneous media with nanosized hydrophobic pockets, where high local concentration of Py is reached, the excimer-like emission can involve the excitation of preassociated ground state dimers, also called "static excimers". Under these conditions, a blue-shifted excimer emission is observed, and the excitation spectrum is dependent on the emission wavelength (25).

According to the above description, the fluorescence behavior of Py in GA microcapsules indicates the formation of static excimer. Thus, it can be expected that ground state Py molecules are constrained to a molecular arrangement that allows a partial overlapping, inducing the formation of the blue-emitting static excimer, in opposition to the symmetrical sandwich-like structure produced in dynamic (or diffusion controlled) excimer formation $(25,26)$. To confirm the formation of the static excimer into the GA microcapsule, we also performed the time-resolved emission spectra (TRES) of Py in GA microcapsule solution (Figure 3C). The time evolution of the TRES indicates that after $1 \mathrm{~ns}$ of the excitation pulse, both the monomer and the excimer emission were observed. This result suggested that the formation of the excimer (i.e., the excimer rise time) is almost instantaneous with the excitation pulse, confirming that the Py molecules into the GA microcapsule are close enough to interact without diffusion. It was observed in the TRES that the fluorescence band of the excimer decays faster than that of the monomer. The analysis of the fluorescence decays at 370 and $460 \mathrm{~nm}$ with eq 4 indicated a main lifetime component of 197 and 34 ns for the monomer and excimer, respectively (data not shown).

The effect of the microcapsulation on the bimolecular quenching of the Py fluorescence by molecular oxygen ${ }^{3} \mathrm{O}_{2}$ was also evaluated by measuring the decreases of the fluorescence lifetime of Py monitored at $370 \mathrm{~nm}$ as a function of the ${ }^{3} \mathrm{O}_{2}$ concentration. The SV plots of eq 5 were linear both in water and in microcapsule solutions (Figure 3D), with bimolecular quenching rate constant $k_{\mathrm{Q}}{ }^{\mathrm{O}_{2}}$ of $1 \times 10^{10}, 8.6 \times 10^{9}$, and $8.4 \times 10^{9} / \mathrm{M}$ s in water and in MD and GA microcapsule solutions, respectively. In spite of the $15 \%$ reduction of $k_{\mathrm{Q}} \mathrm{O}_{2}$, it can be assumed that the biopolymer wall does not considerably modify the diffusion of molecular oxygen within the microcapsule.

The variation of the fluorescence intensity ratios $I_{\mathrm{E}} / I_{\mathrm{M}}$ and $I_{1} / I_{3}$ as a function of the dissolution time was used to evaluate the self-stability of the microcapsules in aqueous solution with the dissolution time (Figure 3E,F). The ratio $I_{\mathrm{E}} / I_{\mathrm{M}}$ decreased approximately $75 \%$ in GA microcapsule solution but increased
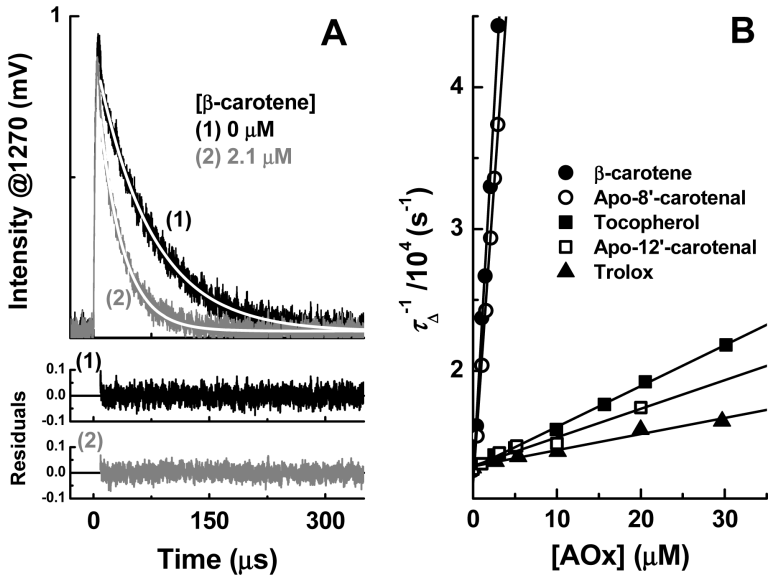

Figure 4. (A) Phosphorescence decay of ${ }^{1} \mathrm{O}_{2}$ in the absence and presence of $\beta$-carotene in acetonitrile solutions. (B) SV plots for the quenching of singlet molecular oxygen $\left({ }^{1} \mathrm{O}_{2}\right)$ by antioxidant molecules in acetonitrile solutions.

almost $64 \%$ in MD microcapsule solution. However, in both cases, the final $I_{\mathrm{E}} / I_{\mathrm{M}}$ value corresponded to that observed in water for a Py solution of the same concentration (Figure 3B). Therefore, the change of the ratio $I_{\mathrm{E}} / I_{\mathrm{M}}$ describes the leaching of the Py molecules from the microcapsules into the bulk solvent. In both types of microcapsules, this process is relatively slow, with an operational half-life of $t_{1 / 2} \approx 17 \pm 3 \mathrm{~h}$ and a lag time of approximately $60 \mathrm{~h}$ for the complete release of the Py molecules. A similar conclusion was obtained by the change of the ratio $I_{1} / I_{3}$ for both microcapsules with the dissolution time (Figure 3F). Initially, for both types of microcapsules, the average $I_{1} / I_{3}$ value sensed by Py into the microcapsule corresponded to that observed in a less polar solvent like dimethyl sulfoxide $\left[I_{1} / I_{3}=2.03, \varepsilon_{\mathrm{r}}=\right.$ 47 (25)]. After $40-60 \mathrm{~h}$ of dissolution, the $I_{1} / I_{3}$ value suddenly decreased to a value much closer to that measured in water $\left[I_{1} / I_{3}=1.83, \varepsilon_{\mathrm{r}}=78(25)\right]$, corresponding to the delivery of Py molecules into the bulk solvent. Interestingly, the reduction of the intensity of the total Rayleigh scattering (measured in the fluorescence spectra) of the microcapsule solutions with the dissolution time yielded similar kinetic parameters to those obtained from the $I_{\mathrm{E}} / I_{\mathrm{M}}$ ratio (data not shown). Considering that the global scattering is proportional to the average particle size, it can be concluded that the delivery of $\mathrm{Py}$ is produced simultaneously with the collapse (or dissolution) of the microcapsule in the aqueous solution.

Quenching of Singlet Oxygen. The capacity of the AOx molecules to quench ${ }^{1} \mathrm{O}_{2}$ was evaluated in acetonitrile, a common organic solvent for the dissolution of these antioxidant molecules, to check the existence of some molecular aggregation effect or changes in the efficiency of photosensitized generation of ${ }^{1} \mathrm{O}_{2}$, in particular for the carotenoids. Figure $\mathbf{4 A}$ shows the typical phosphorescence signal of ${ }^{1} \mathrm{O}_{2}$ obtained after $532 \mathrm{~nm}$ laser excitation of rose bengal in air-saturated acetonitrile solutions. The decay portion of the phosphorescence signal was fitted with the exponential eq 6 , and the quality of the fitting was evaluated by the uniformity of the plot of the residual values. In all cases, the phosphorescence decay was faster as the concentration of the AOx molecules increased, without noticeable changes in the initial phosphorescence intensity $I_{0}$. Thus, the deactivation of ${ }^{1} \mathrm{O}_{2}$ occurs without changes on the efficiency of the photosensitized generation of ${ }^{1} \mathrm{O}_{2}$ by rose bengal. In all cases, linear plots of eq 7 for the variation of $1 / \tau_{\Delta}$ with the AOx concentration were obtained (Figure 4B), suggesting that self-aggregation effects are not occurring in the studied concentration range. The calculated 
Table 2. Rate Constant Value for the Total Quenching of ${ }^{1} \mathrm{O}_{2}$ by Antioxidant Molecules (AOx), $k_{Q}{ }^{A O x} / 10^{7}$ (M s) in Acetonitrile (ACN) and in GA and $M D$ Microcapsules (MC) in $\mathrm{D}_{2} \mathrm{O}$ Solution and Quenching Rate Constant Ratio $R_{\mathrm{Q}}=\left(k_{\mathrm{Q}}{ }^{\mathrm{AOx}}\right)_{\mathrm{MC}} /\left(k_{\mathrm{Q}}{ }^{\mathrm{AOx}}\right)_{\mathrm{ACN}}$

\begin{tabular}{|c|c|c|c|c|c|}
\hline \multirow[b]{2}{*}{ antioxidant (c.d.b. $)^{a}$} & \multirow{2}{*}{$\frac{\text { acetonitrile }}{k_{\mathrm{Q}}{ }^{\mathrm{AO} \times b}}$} & \multicolumn{2}{|c|}{ GA microcapsule } & \multicolumn{2}{|c|}{ MD microcapsule } \\
\hline & & $k_{Q}{ }^{A O \times c}$ & $R_{Q}$ & $k_{Q}{ }^{A O \times b}$ & $R_{Q}$ \\
\hline trolox (3) & $11 \pm 1(6.5 \pm 0.5)^{d}$ & $6.6 \pm 0.3$ & 0.60 & $6.9 \pm 0.2$ & 0.62 \\
\hline$\alpha$-tocopherol (3) & $29 \pm 1$ & $4.1 \pm 0.2$ & 0.14 & $5.5 \pm 0.2$ & 0.19 \\
\hline apo-12'-carotenal (8) & $21 \pm 2$ & $5.4 \pm 0.1$ & 0.26 & $8.2 \pm 0.3$ & 0.39 \\
\hline apo-8'-carotenal (10) & $836 \pm 30$ & $5.5 \pm 0.4$ & 0.007 & $40 \pm 2$ & 0.048 \\
\hline $\begin{array}{l}\beta \text {-carotene (11) } \\
\text { none }^{d}\end{array}$ & $1040 \pm 35$ & $\begin{array}{l}5.1 \pm 0.2 \\
2.7 \pm 0.2^{b}\end{array}$ & 0.005 & $\begin{aligned} 8.6 & \pm 0.4 \\
<0.009 & \pm 0.001\end{aligned}$ & 0.008 \\
\hline
\end{tabular}

${ }^{a}$ C.d.b. $=$ number of conjugated double bonds. ${ }^{b}$ Calculated with eq $7 .{ }^{c}$ Calculated with eq $8 .{ }^{d} \ln \mathrm{D}_{2} \mathrm{O}$ solutions.

$k_{\mathrm{Q}}{ }^{\mathrm{AOx}}$ values (Table 2) are in agreement with reported values $(2,7-11)$. The quenching mechanisms of ${ }^{1} \mathrm{O}_{2}$ by carotenoids and tocopherol derivatives are well-characterized, being governed by an electronic energy-transfer (EET) process in the case of carotenoids and by a charge-transfer (CT) process for tocopherol derivatives (1). Normally, in the EET mechanism the quenching of ${ }^{1} \mathrm{O}_{2}$ is diffusion-controlled (e.g., $k_{\mathrm{Q}} \approx 10^{9}-10^{10} / \mathrm{M} \mathrm{s}$ ) when the triplet state energy of the quencher is smaller than the excitation energy of ${ }^{1} \mathrm{O}_{2}$, that is, $94 \mathrm{~kJ} / \mathrm{mol}$. This condition is completely achieved for carotenoids that contain more than nine conjugated double bonds (c.d.b.), while the $k_{\mathrm{Q}}$ value decreases considerably for carotenoids with lower c.d.b. $(10,11)$, as observed for the carotenoid series $\beta$-carotene (11 c.d.b.), apo- $8^{\prime}$-carotenal (10 c.d.b.), and apo-12'-carotenal (8 c.d.b.). Instead, in the CT-induced deactivation, an electron donation from tocopherol derivatives to ${ }^{1} \mathrm{O}_{2}$ forms an excited singlet state complex (exciplex) $(7-9)$. The singlet exciplex mainly decays by the intersystem crossing to a triplet CT-ground state complex, which finally dissociates to the ground state of the tocopherol and ${ }^{3} \mathrm{O}_{2}$.

The quenching of ${ }^{1} \mathrm{O}_{2}$ by the microencapsulated AOx was studied in $\mathrm{D}_{2} \mathrm{O}$ solutions due to the longer lifetime and larger phosphorescence quantum yield of ${ }^{1} \mathrm{O}_{2}$ in $\mathrm{D}_{2} \mathrm{O}$ than in water (27). As mentioned before, to avoid the slow collapse of the microcapsule in solution $\left(t_{1 / 2} \approx 17 \mathrm{~h}\right)$, the ${ }^{1} \mathrm{O}_{2}$ quenching experiments were performed immediately after the preparation of fresh microcapsule solutions. Under this experimental condition, the phosphorescence of ${ }^{1} \mathrm{O}_{2}$ in microcapsule solution showed firstorder decay, as observed in homogeneous solvent. This behavior can be explained assuming that both the rate of entrance and exit of ${ }^{1} \mathrm{O}_{2}$ in the microcapsules are much higher than its rate of deactivation inside the microcapsules and in bulk $\mathrm{D}_{2} \mathrm{O}$. The pseudofirst order rate constant for the quenching of the Py fluorescence by ${ }^{3} \mathrm{O}_{2}$ in the microcapsule solutions was $k_{\mathrm{Q}}{ }^{\mathrm{O}}\left[\mathrm{O}_{2}\right]$ $\leq 1 \times 10^{7} / \mathrm{s}$ (see above). This value is similar to those reported for the rate of entrance and exit of ${ }^{3} \mathrm{O}_{2}$ (and ${ }^{1} \mathrm{O}_{2}$ ) in micellar pseudophases (28), and it is at least 2 orders of magnitude higher than the decay rate constant of ${ }^{1} \mathrm{O}_{2}$ in $\mathrm{D}_{2} \mathrm{O}$ or in hydrocarbon media (27). Thus, it can be expected that the rate of entrance and exit of a ${ }^{1} \mathrm{O}_{2}$ in the microcapsules occurs at least in hundred nanoseconds.

The UV/vis and emission spectra of rose bengal in maltodextrin solutions were the same as in water or $\mathrm{D}_{2} \mathrm{O}$. In the presence of $\mathrm{GA}$, the absorbance maximum was slightly shifted to the red, but at the laser excitation wavelength at $532 \mathrm{~nm}$, the absorbance change was $<2 \%$ (data not shown). In consequence, no significant changes of the initial phosphorescence signal of ${ }^{1} \mathrm{O}_{2}\left(I_{0}\right)$ were observed in the microcapsules solutions, indicating a similar efficiency of photosensitized generation of ${ }^{1} \mathrm{O}_{2}$ by rose bengal as in homogeneous $\mathrm{D}_{2} \mathrm{O}$. For "empty" microcapsules, the quenching of ${ }^{1} \mathrm{O}_{2}$ by the biopolymers calculated with eq 7 was almost 300 times more efficient for GA than for MD (Figure 5A and Table 2). This large difference between both biopolymers can be related
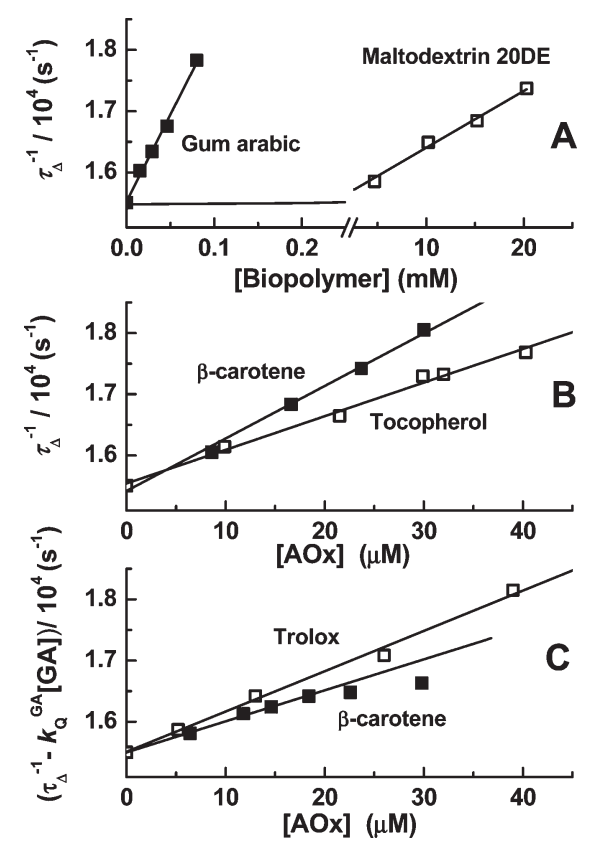

Figure 5. SV plots for the quenching of singlet molecular oxygen $\left({ }^{1} \mathrm{O}_{2}\right)$ in $\mathrm{D}_{2} \mathrm{O}$ solutions by $(\mathbf{A})$ "empty" microcapsules of $\mathrm{GA}$ or $\mathrm{MD},(\mathbf{B}) \beta$-carotene and $\alpha$-tocopherol in MD microcapsules, and (C) $\beta$-carotene and trolox in GA microcapsules.

with the presence of histidine (His) and tyrosine (Tyr) residues in the glycoprotein moiety of GA (22), which are efficient quenchers of ${ }^{1} \mathrm{O}_{2}$ in neutral aqueous media with $k_{\mathrm{Q}}$ values of $4 \times 10^{7}$ and $2.7 \times 10^{7} / \mathrm{M} \mathrm{s}$, respectively $(2,8,27)$. On the contrary, the very weak ${ }^{1} \mathrm{O}_{2}$ quenching by MD can be associated with the presence of $\mathrm{C}-\mathrm{H}$ and $\mathrm{O}-\mathrm{H}$ residues in the polysaccharide, which increase the collisional deactivation of ${ }^{1} \mathrm{O}_{2}$ that proceeds via conversion of the electronic excitation energy into vibrational energy (1). Thus, for the analysis of the quenching of ${ }^{1} \mathrm{O}_{2}$ by the microencapsulated AOx, the intrinsic quenching contribution of MD (as wall material) can be neglected, and the $k_{\mathrm{Q}}{ }^{\mathrm{AOx}}$ were calculated considering the bulk concentration of $\mathrm{AOx}$ with eq 7. However, for the AOx microencapsulated with GA, the intrinsic quenching of ${ }^{1} \mathrm{O}_{2}$ by the biopolymer material must be considered as a parallel process. In this case, the rate of quenching of ${ }^{1} \mathrm{O}_{2}$ by GA is $k_{\mathrm{Q}}^{\mathrm{GA}}[\mathrm{GA}]\left(\right.$ with $k_{\mathrm{Q}}^{\mathrm{GA}}=2.7 \times 10^{7} / \mathrm{M} \mathrm{s}$ ), and the $k_{\mathrm{Q}}{ }^{\mathrm{AOx}}$ is obtained from the slope value of eq 8 .

$$
1 / \tau_{\Delta}-k_{\mathrm{Q}}{ }^{\mathrm{GA}}[\mathrm{GA}]=1 / \tau_{\Delta, 0}+k_{\mathrm{Q}}{ }^{\mathrm{AOx}}[\mathrm{AOx}]
$$

Figure 5B,C shows the typical SV plots obtained with eqs 7 and 8 for some AOx. Except for the apo- $8^{\prime}$-carotenal, all of the microencapsulated AOx showed similar $k_{\mathrm{Q}}{ }^{\mathrm{AOx}}$ values, for example, $5-8 \times 10^{7} / \mathrm{M} \mathrm{s}$ (Table 2). However, a more illustrative difference is obtained by comparing the ratio between the quenching rate 
constant by the AOx in microencapsule and acetonitrile solutions, that is, $R_{\mathrm{Q}}=\left(k_{\mathrm{Q}}{ }^{\mathrm{AOx}}\right)_{\mathrm{MC}} /\left(k_{\mathrm{Q}}{ }^{\mathrm{AOx}}\right)_{\mathrm{ACN}}$ (Table 2). According to this ratio, the quenching process in the microcapsules is strongly dependent on the AOx molecule, since $R_{\mathrm{Q}}$ follows the trend trolox $>$ apo$12^{\prime}$-carotenal $>\alpha$-tocopherol $\gg$ apo- $8^{\prime}$-carotenal $\gg \beta$-carotene. This result can be explained as a combination of the localization of the AOx within the microcapsule and the ${ }^{1} \mathrm{O}_{2}$ accessibility. For trolox, the more polar molecule of the series, the $k_{\mathrm{Q}}{ }^{\mathrm{AOx}}$ value in microcapsule was similar with that found in homogeneous $\mathrm{D}_{2} \mathrm{O}$ solutions, indicating that trolox is located in microdomains of the microcapsule accessible to ${ }^{1} \mathrm{O}_{2}$. On the contrary, for the apolar $\beta$-carotene, a reduction of the $k_{\mathrm{Q}}{ }^{\mathrm{AOx}}$ value of approximately three orders of magnitude was observed in the microcapsule solution as compared with homogeneous solvents (Table 2), indicating a deeper location of $\beta$-carotene within the microcapsule that decreases the probability of collision with ${ }^{1} \mathrm{O}_{2}$.

Lastly, the $R_{\mathrm{Q}}$ value is slightly larger in MD than in GA microcapsules, except for apo- $8^{\prime}$-carotenal as discussed below. This minor difference can be associated with a larger percentage of AOx molecules located in external hydrophobic domains of the MD microcapsule, as indicated by the lower ME values (Table 1). The case of apo- $8^{\prime}$-carotenal in MD microcapsules is remarkable, since it was almost 10 times more efficient as a quencher of ${ }^{1} \mathrm{O}_{2}$ than in GA microcapsules. According to its ME values (Table 1), about 24 and $3.4 \%$ of the carotenal molecules are located in the outer hydrophobic domains of the MD and GA microcapsules, respectively. Considering the large intrinsic quenching capacity of ${ }^{1} \mathrm{O}_{2}$ by apo- $8^{\prime}$-carotenal in acetonitrile $\left(k_{\mathrm{Q}}=8.4 \times 10^{9} / \mathrm{M} \mathrm{s}\right.$, Table 2), this difference in the carotenal distribution in both microcapsules can explain the larger quenching efficiency in MD microcapsules. This is a good example of how the balance between the intrinsic quenching capacity of ${ }^{1} \mathrm{O}_{2}$ and the localization of the AOx molecule within the microcapsule modulates the antioxidant capacity in these systems.

In summary, in the present study, we demonstrated that the morphology and hydrophobic microdomains properties of spraydrying microcapsules are dependent on the nature of the biopolymer used as wall material. The greater molecular complexity of GA in comparison with MD induces the formation of a larger number of hydrophobic microdomains into the microcapsule, allowing enhanced ME.

The quenching rate constant of ${ }^{1} \mathrm{O}_{2}$ by microencapsulated AOx is strongly dependent on the hydrophilic-hydrophobic balance between the AOx molecule and the microcapsule. This effect governs the localization of the AOx within the hydrophobic domains of the microcapsule and, therefore, the probability of interaction with ${ }^{1} \mathrm{O}_{2}$. This is particularly important for apolar AOx such as $\beta$-carotene, since the compartmentalization effects in the hydrophobic microdomains can strongly reduce its intrinsic high quenching capacity toward ${ }^{1} \mathrm{O}_{2}$. Instead, tocopherol derivatives and shorter carotenoids practically retain their quenching capacity in the microcapsules as compared with homogeneous solvents.

Finally, the glycoprotein GA is able to quench ${ }^{1} \mathrm{O}_{2}$, probably due to the presence of aminoacid residues like Tyr and His. The results presented in this work can contribute to the design of new functional antioxidant microcapsules for utilization in both pharmaceutical and food preparations.

\section{LITERATURE CITED}

(1) Schweitzer, C.; Schmidt, R. Physical mechanisms of generation and deactivation of singlet oxygen. Chem. Rev. 2003, 103, 1685-1757.

(2) Lissi, E. A.; Encinas, M. V.; Lemp, E.; Rubio, M. A. Singlet oxygen $\mathrm{O}_{2}\left({ }^{1} \Delta_{\mathrm{g}}\right)$ bimolecular processes. Solvent and compartmentalization effects. Chem. Rev. 1993, 93, 699-723.
(3) Clennan, E. L.; Pace, A. Advances in singlet oxygen chemistry. Tetrahedron 2005, 61, 6665-6691.

(4) Montenegro, M. A.; Nunes, I. L.; Mercadante, A. Z.; Borsarelli, C. D. Photoprotection of vitamins in skimmed milk by aqueous soluble lycopene-Gum arabic microcapsule. J. Agric. Food Chem. 2007, 55, 323-329.

(5) Wilkinson, F. Quenching of electronically excited states by molecular oxygen in fluid solution. Pure Appl. Chem. 1997, 69, 851-858.

(6) Halliwell, B.; Aeschbach, R.; Löliger, J.; Aruoma, O. I. The characterization of antioxidants. Food Chem. Toxicol. 1995, 33, 601-617.

(7) Gorman, A. A.; Gould, I.; Hamblett, I.; Standen, M. C. Reversible exciplex formation between singlet oxygen, $\mathrm{O}_{2}\left({ }^{1} \Delta_{\mathrm{g}}\right)$, and vitamin $\mathrm{E}$. Solvent and temperature effects. J. Am. Chem. Soc. 1984, 106, 69566959.

(8) Bisby, R. H.; Morgan, C. G.; Hamblett, I.; Gorman, A. A. Quenching of singlet oxygen by Trolox, ascorbate, and amino acids: Effects of $\mathrm{pH}$ and temperature. J. Phys. Chem. A 1999, 103, 7454-7459.

(9) Nonell, S.; Moncayo, L.; Trull, F.; Amat-Guerri, F.; Lissi, E. A.; Soltermann, A. T.; Criado, S.; García, N. A. Solvent influence on the kinetics of the photodynamic degradation of trolox, a water-soluble model compound for vitamin E. J. Photochem. Photobiol., B 1995, $29,157-162$.

(10) Baltschun, D.; Beutner, S.; Briviba, K.; Martin, H. D.; Paust, J.; Peters, M.; Rover, S.; Sies, H.; Stahl, W.; Steigel, A.; Stenhorst, F. Singlet oxygen quenching abilities of carotenoids. Liebigs Ann.-Recueil 1997, 9, 1887-1893.

(11) Montenegro, M. A.; Nazareno, M. A.; Durantini, E. N.; Borsarelli, C. D. Singlet oxygen quenching ability of carotenoids in a reverse micelle membrane mimetic system. Photochem. Photobiol. 2002, 75, 353-361.

(12) Deshpande, S. S.; Deshpande, U. S.; Salunkhe, D. K. In Food Antioxidants -Technological, Toxicological, and Health Perspectives; Madhavi, D. L., Deshpande, S. S., Salunkhe, D. K., Eds.; Marcel Dekker: New York, 1996; pp 361-469.

(13) Mercadante, A. Z. Carotenoids in foods: Sources and stability during processing and storage. In Food Colorants-Chemical and Functional Properties; Socaciu, C., Ed.; CRC: New York, 2008; pp $177-192$.

(14) Borsarelli, C. D.; Mercadante, A. Z. Thermal and photochemical degradation of carotenoids. In Carotenoids. Physical, Chemical, and Biological Functions and Properties; Landrum, J. T., Ed.; CRC Press: Boca Raton, 2010; pp 229-253.

(15) Gharsallaoui, A.; Roudaut, G.; Chambin, O.; Voilley, A.; Saurel, R. Applications of spray-drying in microencapsulation of food ingredients: an overview. Food Res. Int. 2007, 40, 1107-1121.

(16) Loksuwan, J. Characteristics of microencapsulated $\beta$-carotene formed by spray drying with modified tapioca starch, native tapioca starch and maltodextrin. Food Hydrocolloids 2007, 21, 928-935.

(17) Barbosa, M. I. M. J.; Borsarelli, C. D.; Mercadante, A. Z. Light stability of spray-dried bixin encapsulated with different edible polysaccharide preparations. Food Res. Int. 2005, 38, 989-994.

(18) Dabestani, R.; Ivanov, I. N. A compilation of physical, spectroscopic and photophysical properties of polycyclic aromatic hydrocarbons. Photochem. Photobiol. 1999, 70, 10-34.

(19) Nunes, I. L.; Mercadante, A. Z. Encapsulation of lycopene using spray-drying and molecular inclusion processes. Braz. Arch. Biol. Technol. 2007, 50, 893-900.

(20) Davies, B. H. In Chemistry and Biochemistry of Plant Pigments; Goodwin, T. W., Ed.; Academic Press: London, 1976; Vol. 2, pp 38-165.

(21) Vieyra, F. E. M.; Zampini, I. C.; Ordoñez, R. M.; Isla, M. I.; Boggetti, H. J.; De Rosso, V. V.; Mercadante, A. Z.; Alvarez, R. M. S.; Borsarelli, C. D. Singlet oxygen quenching and radical scavenging capacities of structurally related flavonoids present in Zuccagnia punctata Cav. Free Radical Res. 2009, 43, 553-564.

(22) Renard, D.; Lavenant-Gourgeon, L.; Ralet, M.-C.; Sanchez, C. Acacia senegal gum: Continuum of molecular species differing by their protein to sugar ratio, molecular weight, and charges. Biomacromolecules 2006, 7, 2637-2649.

(23) Kennedy, J. F.; Noy, R. J.; Stead, J. A.; White, C. A. Oligosaccharide component composition and storage properties of commercial low 
DE maltodextrins and their further modification by enzymatic treatment. Starch/Stärke 1985, 37, 343-351.

(24) Dong, D. C.; Winnik, M. A. The Py scale of solvent polarities. Can. J. Chem. 1984, 62, 2560-2565.

(25) Winnik, F. M. Photophysics of preassociated pyrenes in aqueous polymer solutions and in other organized media. Chem. Rev. 1993, 93, 587-614.

(26) De Schryver, F. C.; Collart, P.; Vandendriessche, J.; Goedeweeck, R.; Swinnen, A.; Van der Auweraer, M. Intramolecular excimer formation in bichromophoric molecules linked by a short flexible chain. Acc. Chem. Res. 1987, 20, 159-166.

(27) Wilkinson, F.; Helman, W. P.; Ross, A. B. Rate constants for the decay and reactions of the lowest electronically excited singlet state of molecular oxygen in solution. An expanded and revised compilation. J. Phys. Chem. Ref. Data 1995, 24, 663-1021.

(28) Lee, P. C.; Rodgers, M. A. J. Singlet molecular oxygen in micellar systems: 1. Distribution equilibria between hydrophobic and hydrophilic compartments. J. Phys. Chem. 1983, 87, 4894-4898.

Received for review March 10, 2010. Revised manuscript received May 19, 2010. Accepted May 21, 2010. We thank the Argentinean Funding Agencies CICyT-UNSE, CONICET, and ANPCyT and the Brazilian Funding Agencies FAPESP and CAPES for their financial support. C.D.B. also thanks the Alexander von Humboldt Foundation for a Georg Foster Fellowship. 